\title{
An abasic site analogue activates a c-Ha-ras gene by a point mutation at modified and adjacent positions
}

Hiroyuki Kamiya, Masayuki Suzuki, Yasuo Komatsu, Hiroyuki Miura, Kanae Kikuchi, Tomoki Sakaguchi, Naoko Murata, Chikahide Masutani ${ }^{1}$, Fumio Hanaoka ${ }^{1}$ and Eiko Ohtsuka* Faculty of Pharmaceutical Sciences, Hokkaido University, Kita-12 Nishi-6, Kita-ku, Sapporo 060 and ${ }^{1}$ Cellular Physiology Laboratory, The Institute of Physical and Chemical Research (RIKEN), Wako, Saitama 351-01, Japan

Received July 8, 1992; Accepted August 6, 1992

\begin{abstract}
ABSRACT
Synthetic c-Ha-ras genes with an analogue of an abasic site in the first or the second position of codon 12, or in the second position of codon 61 were constructed and transfected into NIH3T3 cells. The genes with the lesions in codon 12 exhibited more focus formation than a normal c-Ha-ras gene, while the gene with the lesion in codon 61 did not. Transformed cells were isolated from the foci, and the c-Ha-ras genes present in the transformants were analysed. A point mutation to $A$ in the modified position was found most frequently in the cases of ras genes modified in codon 12. Surprisingly, point mutations in the adjacent position were also detected. These results indicate that dTMP, and not dAMP, was mainly incorporated into the sites opposite to the abasic site analogue, and that incorrect deoxynucleotides were incorporated in the position adjacent to the abasic site analogue.
\end{abstract}

\section{INTRODUCTION}

An abasic (apurinic/apyrimidinic) site is a DNA lesion that is produced by hydrolysis of $N$-glycosyl bonds. The hydrolytic events can occur spontaneously, or by chemical modification of bases (1). They are also generated as intermediates during DNA repair by enzymatic cleavage of the $N$-glycosyl bond of a nucleotide with a modified base, such as uracil, hypoxanthine, or a thymine photodimer (2).

The abasic site lacks a base, and hence has no ability to form the hydrogen bonds that exist in normal base pairs. Therefore, it is very interesting to investigate deoxynucleotide incorporation opposite the abasic site. DNA polymerase has been shown to incorporate dAMP opposite putative abasic sites, which were produced by treatment of dUMP residue-containing DNA with a uracil DNA glycosylase $(3,4)$. In experiments using M13mp2 and $\phi X 174$, dAMP was incorporated opposite putative abasic sites obtained by depurination $(5,6)$. Site-specific mutagenesis experiments using oligodeoxynucleotides with an abasic site, or a chemically stable analogue of an abasic site have been reported. Randall et al. (7) and Takeshita et al. (8) reported the preferential incorporaion of dAMP opposite abasic site analogues by eukaryotic DNA polymerase $\alpha$. Lawrence $e t$ al. constructed single-stranded M13mp7-based vectors with a true abasic site, and found that dAMP was incorporated most frequently (9). This preferential incorporation of dAMP opposite an abasic site is explained by the binding of DATP and DNA polymerases, and by the stacking ability of an adenine base.

It is interesting to determine the types of mutations induced by the abasic sites in an eukaryotic system. Using a system by which the inducibility and the spectra of mutations by DNA lesions were revealed $(10-13)$, we now evaluated these properties of the abasic site. In this paper we describe the transforming activity of c-Ha-ras genes with an analogue of an abasic site in the first or the second position of codon 12, or in the second position of codon 61 . Point mutations induced by the lesion are also reported.

\section{MATERIALS AND METHODS}

\section{Enzymes}

Enzymes were essentially the same as described previously $(10-13)$.

Synthesis of oligonucleotides with an abasic site analogue A phosphoramidite for an abasic site analogue (5-O(4,4'-dimethoxytrityl)-1,4-anhydro-2-deoxy-D-ribitol\} was synthesized according to the method described by Eritja et al. (14). The compound was phosphitylated using 2-cyanoethyl $N, N$ diisopropylchlorophosphoramidite (Sigma Chemical Co.).

Oligonucleotides containing an abasic site analogue were synthesized by the phosphoramidite method with an Applied Biosystems model 380A DNA synthesizer and a model 394 DNA/RNA synthesizer. The oligonucleotides were purified by reverse phase HPLC (before and after detritylation with $80 \%$ acetic acid) and anion exchange HPLC, as described previously (15). 


\section{Construction of c-Ha-ras genes with an abasic site analogue at codon 12}

Preparation of DNA cassettes with an abasic site analogue in the first or the second position of codon 12, and construction of c-Ha-ras vectors by a DNA cassette technique were carried out as described previously $(10-12)$. Control vectors having a GGC (Gly-12, normal), a GAC (Asp-12, activated), or a GTC (Val-12, activated) sequence at codon 12 were constructed in the same manner.

\section{Construction of a c-Ha-ras vector with an abasic site analogue at codon 61}

Preparation of a DNA cassette containing an abasic site analogue in the second position of codon 61 , and construction of a c-Haras vector were carried out as described previously (13) with one modification. A new plasmid, pEB (Fig. 2b), with a noncoding sequence between the $E c o \mathrm{RV}$ and $B c l$ sites, was constructed by exchanging the $E c o R V-B c l$ fragment of pRSVras (13) with the corresponding noncoding fragment. The vector for the transfection assay was constructed using this plasmid. Control vectors having a CAA (Gln-61, normal) or a CTA (Leu-61, activated) sequence at codon 61 were constructed in the same manner.

\section{DNA transfection assay}

The vectors carrying a c-Ha-ras gene were transfected by the calcium phosphate method as described previously $(16,17)$.

\section{Analysis of c-Ha-ras genes present in transformants}

Analysis of the first and the second positions of codon 12 was done by the polymerase chain reaction-restriction enzyme (PCRRE) method, as described previously $(10-12,18)$. Specifically, the sequence around codon 12 of the ras gene present in the transformed cells was amplified by the PCR (19). The primers used for the PCR were Seq1 (dTTTTTTATCGATGACGGAATATAAG) $(11,12)$ and L10 (dAAAAGATTTGGTGTTGTTGATAGCGAAAACGCACAG) (15). The amplified and purified PCR products were subjected to nucleotide analysis. A mutagenic primer, dAAGCTGGTGGTGGTGGNGGCC, which corresponds to the human c-Ha-ras sequence from codon 5 to codon 11, except for the italicized $G$ and $\mathrm{N}$ (N was replaced by $\mathrm{T}, \mathrm{A}$, or G), was used in the second PCR together with L12 (dCAGAGTATTCTTCTTGGCCTG) (15) for analysis of the first position of codon 12 . The products were then incubated with MscI (for detection of a mutation to A), StuI (for a mutation to T), or ApaI (for a mutation to C), and analysed by polyacrylamide gel electrophoresis (PAGE) (12). For analysis of the second position of codon 12, a mutagenic primer, dAAGCTGGTGGTGGTGGGCGNCG (N was replaced by T, A, or G), was used together with L12. The products were incubated with Sall (for detection of a mutation to A), AatII (for a mutation to T), or $B b e I$ (for a mutation to C), and analysed by PAGE $(10,11)$. For detection of a normal (with $G$ in both the first and the second positions) c-Ha-ras gene, dAAGCTGGTGGTGGTGGGCGCC was used instead of the mutagenic primer, and the product was digested with either HapII or NaeI.

\section{In vitro replication of DNA templates with an abasic site analogue}

DNA templates with an abasic site analogue were prepared by enzymatic joining of HRU1, HRU2, and HRU3, using HRL1 as a splint. The ligation products were purified by denaturing

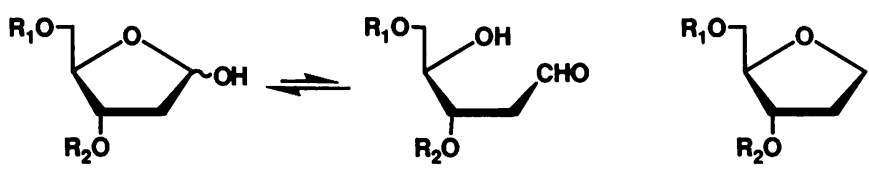

Figure 1. Structures of an abasic site (left) and its analogue, F (right).

(8M urea) $20 \%$ PAGE. The templates were annealed with a primer, Seq 2 (Fig. 4), and were replicated by Taq DNA polymerase or mouse DNA polymerase $\alpha$-primase (purified from FM3A cells (20)\}, using the conditions described previously (19, $21)$. The duplex DNA was purified by PAGE. In the case of Taq DNA polymerase, the double-stranded DNA was directly analysed. In the case of DNA polymerase $\alpha$, the replicated DNA was digested with AluI. After purification by PAGE, the DNA was treated with $\lambda$ exonuclease as described (22). Incorporated nucleotides were analysed by the PCR-RE method as described above, except Seq 2 was used instead of L12.

\section{RESULTS}

Construction of c-Ha-ras vectors with an abasic site analogue at codon 12 or codon 61

We have reported the synthesis of c-Ha-ras genes with a DNA lesion at codon $12\left(O^{6}\right.$-methylguanine, 8-hydroxyguanine, or xanthine) or at codon 61 (hypoxanthine), and their transforming activities in NIH3T3 cells $(10-13)$. In these reports we described DNA cassette mutagenesis techniques to incorporate the lesion in a specific position in the c-Ha-ras gene. These techniques were also used in this study.

A portion of a parental vector, $\mathrm{pCB}$, and DNA cassettes with an abasic site analogue (tetrahydrofuran derivative, abbreviated as F, hereafter (Fig. 1) \} in the first or the second position of codon 12 (the 34th or the 35th position, respectively) are shown in Fig. 2a. The cassettes were inserted into the vector after digestion with $\mathrm{ClaI}$ and BssHII, as described previously $(10-12)$.

When c-Ha-ras genes containing an 8-hydroxyguanine or xanthine were constructed, we used $\mathrm{pCB}$, which has a noncoding sequence between the ClaI and BssHII sites, to reduce transformation of NIH3T3 cells by a normal c-Ha-ras gene (11, 12). A similar strategy was employed to construct a c-Ha-ras vector with $F$ in the second position of codon 61 (position 182). Namely, a new plasmid, $p E B$, which has a noncoding sequence between the $E c o R V$ and $B c l I$ sites, was constructed and the vector was used to insert the DNA cassette with F (Fig. 2b).

Transforming activity of $\mathbf{c}$-Ha-ras genes with an abasic site analogue

The vector constructs and the controls were transfected into NIH3T3 cells. Table 1 shows the number of foci induced by the c-Ha-ras genes with $\mathrm{F}$ at codon 12 and by the control (normal and activated) c-Ha-ras genes. Both of the c-Ha-ras genes with $\mathrm{F}$ (represented as the $34 \mathrm{~F}$ - and the $35 \mathrm{~F}$-ras genes) induced more foci than the normal c-Ha-ras gene, indicating that an abasic site (analogue) was mutagenic. It seemed that the 35F-ras gene had more transforming activity than the 34F-ras gene. The transforming efficiency of the c-Ha-ras genes with $\mathrm{F}$ was about 10 percent of that of the activated (Val-12 or Asp-12) c-Ha-ras genes. Although the analogue $\mathrm{F}$ is chemically stable and resistant to $\beta$-elimination, $\mathrm{F}$ is recognised by an apurinic/apyrimidinic site 


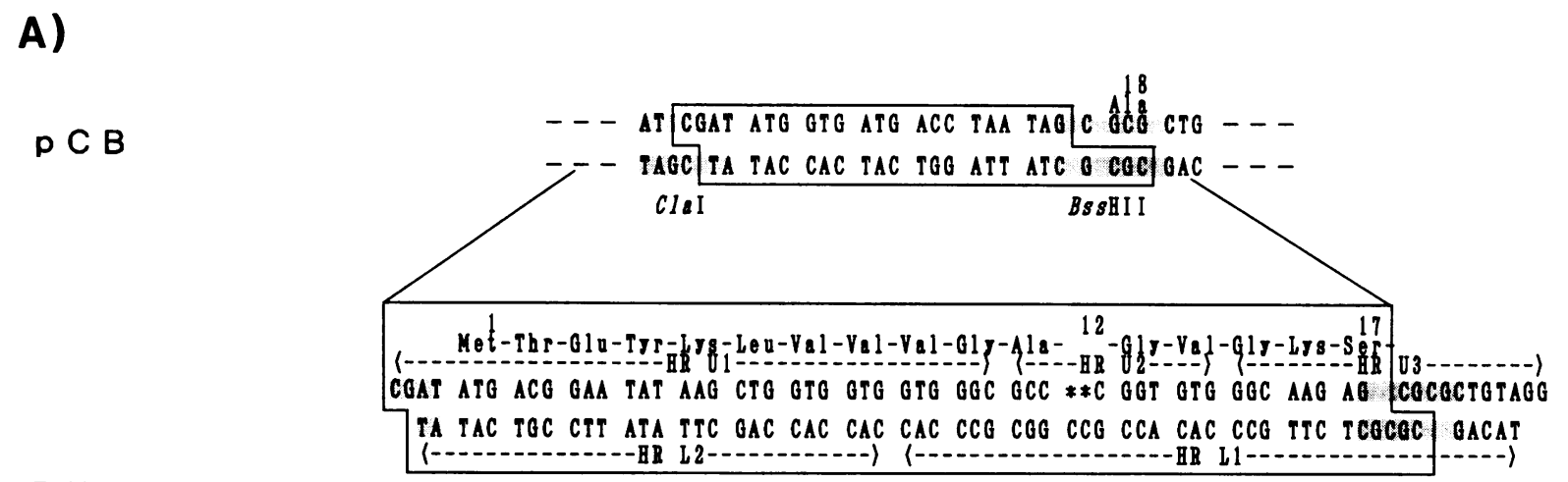

DNA casset te

B)

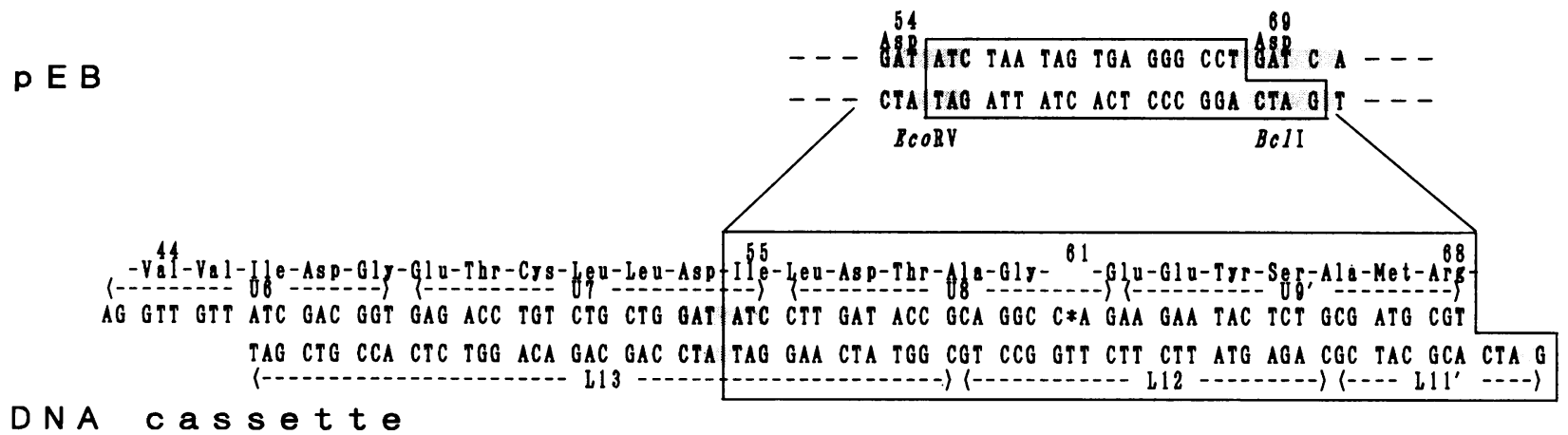

Figure 2. Generation of a synthetic c-Ha-ras gene with an abasic site analogue in the first or the second position of codon 12 (A), and in the second position of codon 61 (B). A) DNA cassettes with an abasic site analogue in codon 12 were inserted into pCB, which had been digested with ClaI and BssHII. B) A DNA cassette with an abasic site analogue in codon 61 was inserted into PEB, which had been digested with EcoRV and Bcll. The positions of the abasic site analogue and the restriction enzyme sites are indicated by asterisks and shading, respectively.

endonuclease (23-25). It is likely that this enzyme in NIH3T3 cells removed the $\mathrm{F}$ residue. On the other hand, a c-Ha-ras gene with $\mathrm{F}$ at codon 61 (182F-ras gene) induced foci to a similar level as a normal c-Ha-ras gene (Table 2). The discrepancy between the results of codon 12 and codon 61 may arise from differences in the nucleotide sequences around $\mathrm{F}$, which may be related to the efficiencies of repair. An alternative explanation is that the DNA polymerase(s) in NIH3T3 cells did not 'misread' $F$ in the case of codon 61 . This possibility will be addressed in the Discussion.

\section{Sequence analysis of c-Ha-ras genes present in transformants}

The c-Ha-ras genes present in the transformants were analysed by the PCR-RE method $(10-12,18)$. The principle of this method is that a point mutation at the site of interest forms a certain restriction enzyme site by introducing the second mutation(s) by a mutagenic primer in a position other than the investigated position. The novel site is cleaved by a restriction enzyme in a sequence-specific manner. The original sequence from codon 10 to codon 11 in the c-Ha-ras gene is GGCGCC, and the mutagenic primer for the 34th position changes this sequence to GNGGCC. When the 34th position is mutated to A, and $N$ is T, the sequence GTGGCCA is formed, and ras gene fragments with this sequence can be cleaved with MscI, which
Table 1. Number of Foci Induced by c-Ha-ras Genes

\begin{tabular}{|c|c|c|c|c|c|c|}
\hline \multirow{2}{*}{ Codon 12} & \multicolumn{6}{|c|}{ Experiment No. } \\
\hline & 12) & 2b) & 3 a) & $4^{b)}$ & $5^{2)}$ & $6^{\mathrm{b})}$ \\
\hline$\underset{(\text { Gly-12) }}{\text { GGC }}$ & 6 & 16 & 0 & 6 & 0 & 4 \\
\hline$\underset{(34 F)}{\text { FGC }^{d)}}$ & 14 & 42 & 5 & 16 & 5 & 17 \\
\hline$\underset{(35 F)}{G F C^{d)}}$ & 9 & 44 & 7 & 28 & 10 & 27 \\
\hline$\underset{(\text { Asp-12) }}{\text { GAC }}$ & $>100$ & $>100$ & $N D^{c)}$ & $N D^{c)}$ & $N D^{c)}$ & $N D^{c)}$ \\
\hline$\underset{(\mathrm{V} \text { al-12) }}{\text { GTC }}$ & $N D^{c)}$ & $N D^{c)}$ & 79 & 110 & 111 & 148 \\
\hline
\end{tabular}

a) Fifty ng of DNA was used.

b) One hundred fifty ng of DNA was used.

c) ND, not determined.

d) F, abasic site analogue.

recognises a TGGCCA sequence. In a similar fashion, it is possible to detect any point mutations of the 34th or 35th positions by combination of an appropriate mutagenic primer and a restriction enzyme. 
Table 2. Number of Foci Induced by c-Ha-ras Genes

\begin{tabular}{ccccc}
\hline & \multicolumn{4}{c}{ Experiment No. } \\
\cline { 2 - 5 } Codon 61 & $1^{\text {a) }}$ & $2^{\text {b) }}$ & $3^{\text {a) }}$ & $4^{\text {b) }}$ \\
\hline $\begin{array}{c}\text { CAA } \\
(\text { GIn-61) }\end{array}$ & 2 & 4 & 7 & 15 \\
$\underbrace{\left.\text { CFA }^{c}\right)}_{(182 F)}$ & 1 & 9 & 7 & 27 \\
$\begin{array}{c}\text { CTA } \\
(\text { Leu-61) }\end{array}$ & 84 & 242 & 75 & 260 \\
\hline
\end{tabular}

a) One hundred fifty ng of DNA was used.

b) Five hundred ng of DNA was used.

c) $F$, abasic site analogue.

The results of the PCR-RE analysis of a transformant obtained by transfection of the 34F-ras gene are shown in Fig. 3a. In this case, cleavage was observed only when the PCR product was treated with MscI (lane 6) indicating that the 34th position was mutated to $\mathrm{A}$. The results from a transformant obtained by transfection of the 35F-ras gene are shown in Fig. 3b. Cleavage was observed after treatment of the PCR product with AatII (lane $2)$. This indicates that the 35th position was replaced with $\mathrm{A}$. Table 3 summarises the results of the analysis. In the case of the transformants induced by the 34F-ras gene, the most frequently found mutation was to A (12 clones / 33 clones analysed). Mutations to $\mathrm{T}$ and $\mathrm{C}$ were also detected. Surprisingly, mutations in the $3^{\prime}$-flanking site (the second position of codon 12 , the 35th position) were detected. The mutation found most frequently in the flanking site was a mutation to A (9 clones / 33 clones analysed), although mutations to $\mathrm{T}$ and $\mathrm{C}$ in the adjacent position were also detected. Mutation to $\mathrm{A}$ in the flanking position occurred more frequently than mutations to $\mathrm{T}$ or $\mathrm{C}$ in the modified position. In the case of the transformants that were induced by the 35F-ras gene, the mutation found most frequently was also a mutation to A (16 clones / 32 clones analysed). A mutation to $\mathrm{T}$ was also detected. Mutations in the 5 '-flanking site (the first position of codon 12 , the 34 th position) to $\mathrm{A}, \mathrm{T}$ and $\mathrm{C}$ were detected. In these cases, the occurrence of the flanking mutations was not frequent, and mutation to $T$ was most commonly observed. Some transformants did not have a mutated ras gene and seemed to contain a normal c-Ha-ras gene. This conclusion was supported by the susceptibility of the PCR products to digestion with HapII or NaeI, which recognise CCGG or GCCGGC sequences that exist in the normal gene (data not shown). Since the ratio of (foci induced by normal ras gene) / (foci induced by the 34F- or the 35F-ras gene) was similar to the ratio of (the normal ras genes) / (all ras genes analysed), the existence of a normal ras gene in the transformants may be explained by focus-formation caused by the overproduction of normal c-Ha-ras proteins (26).

Cells that formed a focus by transfection of the 182F-ras gene were analysed in a similar way by the PCR-RE method. Among the 11 cells analysed, no mutated genes were detected in either position of codon 61 (data not shown). It is likely that the focusformed cells obtained by the transfection with the 182F-ras gene were transformed by overexpression of normal c-Ha-ras proteins (26).

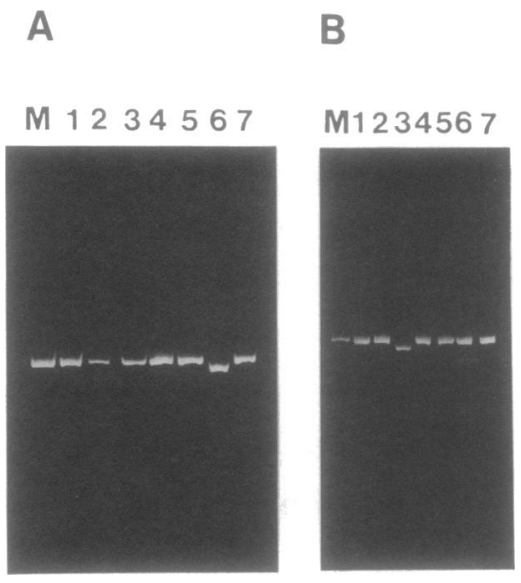

Figure 3. Sequence analysis of c-Ha-ras genes present in the transformed NIH3T3 cells. A) Analysis of the clone obtained with c-Ha-ras with an abasic site analogue in the first position of codon 12. B) Analysis of the clone obtained with c-Ha-ras with an abasic site analogue in the second position of codon 12. Lane 1; HapII digestion for detection of a normal c-Ha-ras gene. Lanes 2-4 ; analysis of the second position of codon 12, AatII for T (lane 2), Sall for A (lane 3), and BbeI for C (lane 4). Lanes 5-7 ; analysis of the first position of codon 12, StuI for T (lane 5), MscI for A (lane 6), and ApaI for C (lane 7). M corresponds to the PCR product without restriction enzyme treatment.

Table 3. Mutations induced by ras genes

\begin{tabular}{|c|c|c|c|}
\hline \multicolumn{2}{|c|}{ ras gene } & \multirow{2}{*}{$\frac{34 \mathrm{~F}-\mathrm{ras}}{12 / 33^{\mathrm{a})}}$} & \multirow{2}{*}{$\frac{35 F-r a s}{1 / 32}$} \\
\hline mutation & A & & \\
\hline $\begin{array}{l}\text { In the } \\
34 \text { th }\end{array}$ & $\mathrm{T}$ & $3 / 33^{b)}$ & $3 / 32^{d)}$ \\
\hline position & C & $2 / 33^{c)}$ & $1 / 32^{e)}$ \\
\hline \multirow{3}{*}{$\begin{array}{l}\text { mutation } \\
\text { In the } \\
\text { 35th } \\
\text { position }\end{array}$} & A & $9 / 33^{a, b, c)}$ & $16 / 32^{d, e)}$ \\
\hline & $T$ & $2 / 33$ & $4 / 32$ \\
\hline & C & $2 / 33$ & $0 / 32$ \\
\hline $\begin{array}{l}\text { normal } \\
\text { gene }\end{array}$ & & $8 / 33$ & $10 / 32$ \\
\hline
\end{tabular}

a) $34 A+35 A, 2 / 33$

b) $34 T+35 A, 1 / 33$

c) $34 \mathrm{C}+35 \mathrm{~A}, 1 / 33$

d) $34 T+35 A, 2 / 32$

e) $34 \mathrm{C}+35 \mathrm{~A}, 1 / 32$

Deoxynucleotide incorporation opposite an abasic site analogue in vitro

The nucleotide sequences of a template DNA with $F$ in the position corresponding to the 34th or 35th position of the c-Haras gene, and a primer, Seq 2 are shown in Fig. 4. The templates were the same three oligonucleotides as used in the construction of the DNA cassettes (Fig. 2a). As shown in Fig. 5, the templates were replicated by either Taq DNA polymerase or mouse DNA polymerase $\alpha$-primase complex. The replication products from by Taq DNA polymerase were analysed directly by the PCRRE method (method A). The products from DNA polymerase $\alpha$ were digested with $A l u I$ to generate 5'-phosphorylated blunt 
Figure 4. Nucleotide sequences of a DNA template and a primer for in vitro replication study. A DNA template, corresponding to a c-Ha-ras fragment around codon 12 , and a primer, Seq 2 , are shown. The positions of the abasic site analogue and the AluI sequence are indicated by asterisks and shading, respectively.

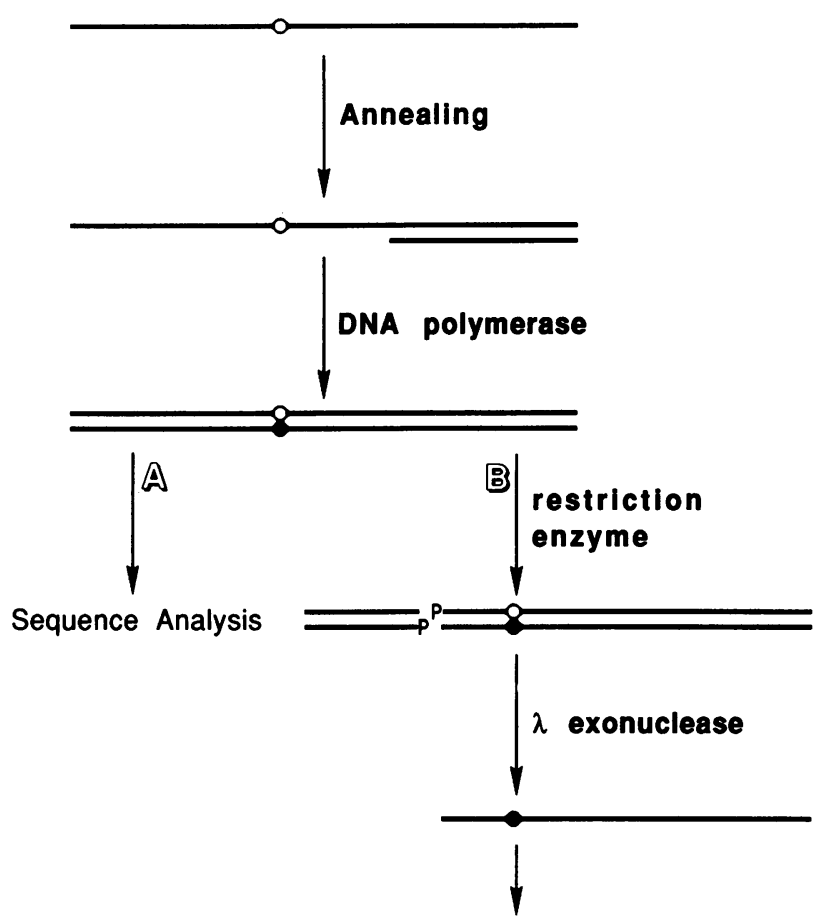

Sequence Analysis

Figure 5. Schemes for replication of a DNA template with an abasic site analogue, and analysis of the product. A DNA template was annealed with a primer (Seq 2) and replicated by a DNA polymerase. In the case of Taq DNA polymerase, the replicated DNA was directly analysed (method A). The DNA replicated by mouse DNA polymerase $\alpha$-primase complex was digested with AluI. After purification by PAGE, the DNA was treated with $\lambda$ exonuclease and analysed (method B). Open circles and closed circles indicate the modified positions and the opposite positions, respectively. $\mathrm{P}$ indicates $5^{\prime}$-phosphate groups.

ends. After separation from the uncleaved DNA, the fragments were treated with $\lambda$ exonuclease, which preferentially recognises a 5'-phosphorylated blunt end and hydrolyses the strand possessing a 5'-phosphate. The single strands that lacked an abasic site analogue were analysed by the PCR-RE method (Fig. 5, method B). Fig. 6 shows the results of 34F and 35F-templates after replication by DNA polymerase $\alpha$. Cleavage of the PCR products was observed only upon incubation with StuI (34F) or AatII (35F), indicating that dAMP was incorporated opposite F in both cases. Similarly, Taq DNA polymerase inserted only dAMP (data not shown). In all cases, incorporation of incorrect deoxynucleotides in the adjacent position was not detected.

\section{DISCUSSION}

We have reported the inducibility and the spectra of mutations caused by $O^{6}$-methylguanine, xanthine, or 8-hydroxyguanine at codon $12(10-12)$, and hypoxanthine at codon 61 (13) of the
A

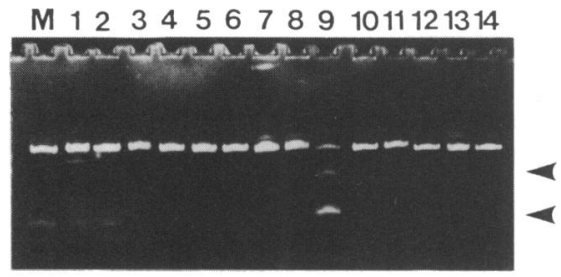

B

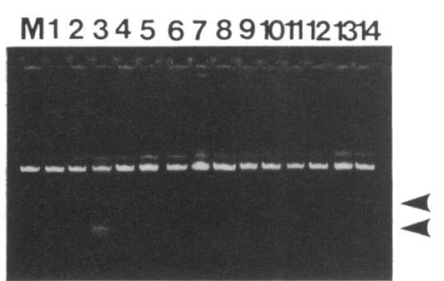

Figure 6. Sequence analysis of replicated products of mouse DNA polymerase $\alpha$. Incorporation of dAMP, dTMP, and dGMP corresponding to the 35th position in the complementary strand is indicated by cleavage of the PCR products by AatII, SalI, and BbeI, respectively. Incorporation of dAMP, dTMP, and dGMP corresponding to the 34th position in the complementary strand is indicated by cleavage of the PCR products by StuI, MscI, and ApaI, respectively. HapII cleavage was carried out for detection of ACMP incorporation at both sites. To confirm the cleavage, the controls, which were not digested with the enzyme, are also shown (samples with restriction enzyme treatment are indicated as HapII + , and those without treatment are shown as HapII -, for example). A) Analysis of 34F-template. B) Analysis of 35F-template. Lane 1, Hap II +; lane 2, HapII -; lane 3, AatII +; lane 4, AatII -; lane 5, SalI +; lane 6, SalI -; lane 7, BbeI +; lane 8, BbeI -.; lane 9, StuI +; lane 10, StuI -; lane 11, MscI +; lane 12, MscI -; lane 13, ApaI +; lane 14, ApaI -; M, an uncleaved PCR product. Arrowheads indicate cleaved products.

c-Ha-ras gene. This site-specific mutagenesis technique is applicable to other DNA lesions. The system depends on the principle that the ras gene is activated, thereby transforming the transfected NIH3T3 cells when a change occurs in the amino acid corresponding to the position where a DNA lesion is introduced (the 12th or the 61st amino acid of a ras protein) (27, 28). We adapted this system to study a premutagenic DNA lesion, an abasic site. Although the abasic site can be produced either by depurination or by depyrimidination, we chose to study depurination events in a c-Ha-ras gene and introduced the abasic site at the first and second positions of codon 12 (GGC), and at the second position of codon 61 (CAA). Since a true abasic site is alkali-labile, a chemically-stable analogue of the abasic site, a tetrahydrofuran derivative (Fig. 1), was used in order to avoid degradation during the construction of the modified c-Haras gene.

When the 34F- and the 35F-ras genes were transfected into NIH3T3 cells, both showed more focus-forming activity than a normal c-Ha-ras gene (Table 1). These results suggest that an abasic site in the 34 th or the 35 th position can activate the c-Haras gene. 
Sequence analysis of the transformants induced by the $34 \mathrm{~F}$ or the $35 \mathrm{~F}$-ras gene revealed that a point mutation to A was most frequent in both cases (Table 3 ). These results suggest that dTMP, and not dAMP, was incorporated with the highest frequency in NIH3T3 cells. It has been reported that dAMP was incorporated most frequently into the site opposite to the abasic site in both in vitro and prokaryotic systems $(3-6,9)$. Five explanations are possible for this discrepancy between the present findings in a mammalian system and the results from the in vitro and prokaryotic systems. First, the differences in the sequences may have a large effect on nucleotide-incorporation. Second, the conformation of the duplex with the analogue is different from that with a true abasic site $(29,30)$, which may have an effect on nucleotide-incorporation. Third, DNA polymerase(s) other than DNA polymerase $\alpha$, which is actually involved in replication, may preferentially insert dTMP. Fourth, other proteins involved in replication may alter the selectivity of DNA polymerase(s). Lastly, the proof-reading mechanism may remove an A opposite an abasic site (analogue). The first possibility is not likely because DNA polymerases (Taq DNA polymerase and mouse DNA polymerase $\alpha$-primase complex) incorporated dAMP opposite $F$ in the corresponding sequence in vitro (Fig. 6). The second possibility is not true because Takeshita $e t$ al. and Randall et al. demonstrated that dAMP was preferentially incorporated opposite the chemically-stable analogue of an abasic site, F, which was used in this study, by DNA polymerases, including eukaryotic DNA polymerase $\alpha(7,8)$. Therefore, the discrepancy must be due to one or more of the last three reasons.

The sequence analysis also showed a point mutation flanking the abasic site analogue. Both the 3 '-side of 34F (the 35th position) and the $5^{\prime}$-side of $35 \mathrm{~F}$ (the 34 th position) were the positions in which a mutation can activate the c-Ha-ras gene. On the other hand, the $5^{\prime}$-side of $34 \mathrm{~F}$ (the third position of codon 11 ) and the 3 '-side of $35 \mathrm{~F}$ (the third position of codon 12) were not potentially activating positions because substitution of the third position of codon 11 or 12 does not alter an amino acid in the c-Ha-ras protein (the 11th and the 12th amino acid were Ala and Gly, respectively).

It has been suggested that the incorporation of a deoxynucleotide opposite the 3 '-position of an abasic site (analogue) has a larger effect than incorporation at the site opposite to the 5'-site of the lesion, because the ratio of (transformants possessing a mutation in the 35th position) / (all analysed transformants) in the case of the 34F-ras gene was larger than that of (transformants possessing a mutation in the 34th position) / (all analysed transformants) in the case of the 35Fras gene (Table 3 ).

Recently, Gentil et al. reported the random insertion of nucleotides opposite an abasic site in COS cells (31). Their results resemble our present finding. However, they observed that dAMP was incorporated at a similar level to dTMP. Our results indicate that dTMP was incorporated opposite $F$ most frequently. Furthermore, we observed point mutations in the adjacent positions. These investigators used a shuttle vector, which existed as a plasmid in the cells. The vector may be replicated by a different DNA polymerase than those involved in the replication of DNA on chromosomes. It is possible that such differences between DNA polymerases and nucleotide sequences may yield distinct results.

The c-Ha-ras gene with $\mathrm{F}$ in the second position of codon 61 (182F-ras gene) did not induce a point mutation. This result is in contrast to the results of the $34 \mathrm{~F}$ - and the $35 \mathrm{~F}$-ras genes. The difference in mutation-inducibility may be related to the repair efficiency, which is thought to be sequence-dependent. An abasic site (analogue) in the 182 nd position may be repaired faster than one in the 34th or the 35th position. An alternative explanation is that the preferential incorporation of dTMP opposite F did not activate the $182 \mathrm{~F}$-ras gene because the original sequence of codon 61 is CAA. The $3^{\prime}$-site of $182 \mathrm{~F}$ is also $\mathrm{A}$, and the incorporation of dTMP opposite this position did not alter the 61st amino acid. The first position of codon 61 is the other potential activating position and the $5^{\prime}$-flanking site of $182 \mathrm{~F}$. The frequency of a mutation in the 5'-site of $\mathrm{F}$ may be relatively small, as mentioned above. Although the incorporation of an incorrect nucleotide can activate a ras gene by altering the 61 st amino acid, this type of event might not occur at the 5'-site of the 182F-ras gene.

Abasic site analogues in the first or the second position of codon 12 induced various point mutations in the modified and adjacent positions. These results were somewhat analogous to our previous results when 8-hydroxyguanine was introduced into the second position of codon 12 (12). The modified base is removed by a specific repair enzyme and an abasic site is produced in Escherichia coli $(32,33)$. Although it is not clear whether the mammalian enzyme $(34,35)$ works in a similar way, it is possible that the introduced 8-hydroxyguanine was removed as a free base, and an abasic site was created in NIH3T3 cells. Mutations induced by the modified guanine may be partly derived from the abasic site.

In this study, we showed that c-Ha-ras genes with an abasic site analogue in the first or the second position of codon 12 induced foci when transfected into NIH3T3 cells. We also demonstrated that the analogue caused various point mutations, both in the modified and in the adjacent positions. In order to investigate the mutation-spectrum of an abasic site in a mammalian system, it is better to use a genuine abasic site. A genuine abasic site is alkali-labile, so it is difficult to use the method described in this paper. Site-directed mutagenesis experiments of a true abasic site, using improved techniques are in progress.

\section{ACKNOWLEDGEMENT}

This work was supported in part by a Grant-in-Aid from the Ministry of Education, Science and Culture, Japan.

\section{REFERENCES}

1. Loeb, L. A. and Preston, B. D. (1986) Ann. Rev. Genet. 20, 201-230.

2. Sancar, A. and Sancar, G. B. (1988) Ann. Rev. Biochem. 57, 29-67.

3. Boiteux, S. and Laval, J. (1982) Biochemistry 21, 6746-6751.

4. Sagher, D. and Strauss, B. (1983) Biochemistry 22, 4518-4526.

5. Schaaper, R. M., Kunkel, T. A., and Loeb, L. A. (1983) Proc. Natl. Acad. Sci. USA 80, 487-491.

6. Kunkel, T. A. (1984) Proc. Natl. Acad. Sci. USA 81, 1494-1498.

7. Randall, S. K., Eritja, R., Kaplan, B. E., Petruska, J. and Goodman, M. F. (1987) J. Biol. Chem. 262, 6864-6870.

8. Takeshita, M., Chang, C.-N., Johnson, F., Will, S. and Grollman, A. P. (1987) J. Biol. Chem. 262, $10171-10179$.

9. Lawrence, C. W., Borden, A., Banerjee, S. K. and LeClerc, J. E. (1990) Nucleic Acids Res. 18, 2153-2157.

10. Kamiya, H., Miura, K., Ohtomo, N., Nishimura, S. and Ohtsuka, E. (1991) Jpn. J. Cancer Res. 82, 997-1002.

11. Kamiya, H., Shimizu, M., Suzuki, M. Inoue, H. and Ohtsuka, E. (1992) Nucleosides and Nucleotides 11, 247-260.

12. Kamiya. H., Miura, K., Ishikawa, H., Inoue, H., Nishimura, S. and Ohtsuka, E. (1992) Cancer Res. 52, 3483-3485.

13. Kamiya, H., Miura, H., Kato, H., Nishimura, S. and Ohtsuka, E. (1992) Cancer Res. 52, 1836-1839. 
14. Eritja, R., Walker, P. A., Randall, S. K., Goodman, M. F. and Kaplan, B. E. (1987) Nucleosides and Nucleotides $6,803-814$.

15. Miura, K., Inoue, Y.,Nakamori, H., Iwai, S., Ohtsuka, E., Ikehara, M., Noguchi, S. and Nishimura, S. (1986) Jpn. J. Cancer Res. 77, 45-51.

16. Kamiya, H., Miura, K., Ohtomo, N., Koda, T., Kakinuma, M., Nishimura, S. and Ohtsuka, E. (1989) Jpn. J. Cancer Res. 80, 200-203.

17. Perucho, M., Goldfarb, M., Shimizu, K., Lama, C., Fogh J. and Wigler, M. (1981) Cell 27, 467-476.

18. Haliassos, A.,Chomel, J. C.,Grandjouan, S., Kruh, J., Kaplan, J. C. and Kitzis, A. (1989) Nucl. Acids Res. 17, 8093-8099.

19. Saiki, R. K., Gelfand, D. H., Stoffel, S., Sharf, S. J., Higuchi, R.,Horn, G. T., Mullis, K. B. and Elrich, H. A. (1988) Science 239, 487-491.

20. Takada-Takayama, R., Tada, S., Hanaoka, F. and Ui, M. (1990) Biochem. Biophys. Res. Comm. 170, 589-595.

21. Suzuki, M., Enomoto, T., Masutani, C., Hanaoka, F. and Ui, M. (1989) J. Biol. Chem. 264, 10065-10071.

22. Higuchi, R. G. and Ochman, H. (1989) Nucleic Acids Res. 17, 5865.

23. Sanderson, B. J. S., Chang, C.-N., Grollman, A. P. and Henner, W. D. (1989) Biochemistry 28, 3894-3901.

24. Matsumoto, Y. and Bogenhagen, D. F. (1989) Mol. Cell. Biol. 9, $3750-3757$

25. Matsumoto, Y. and Bogenhagen, D. F. (1991) Mol. Cell. Biol. 11, 4441-4447.

26. Chang, E. H., Furth, M. E., Scolnick, E. M. and Lowy, D. R. (1982) Nature 297, 479-483.

27. Seeburg, P. H., Colby, W. W., Capon, D. J., Goeddel, D. V. and Levinson, A. D. (1984) Nature 312, 71-75.

28. Der, C. J., Finkel. T. and Cooper, G. M. (1986) Cell 44, 167-176.

29. Kalnik, M. W., Chang, C.-N., Grollman, A. P. and Patel, D. J. (1988) Biochemistry 27, 924-931.

30. Withka, J. M., Wilde, J. A. and Bolton, P. H. (1991) Biochemistry 30, 9931-9940.

31. Gentil, A., Renault, G., Madzak, C., Margot, A., Cabral-Neto, J. B., Vasseur, J. J., Rayer, B., Imbach, J. L. and Sarasin, A. (1990) Biochem. Biophys. Res. Comm. 173, 704-710.

32. Chung, M.-H., Kasai, H., Jones, D. S., Inoue, H., Ishikawa, H., Ohtsuka, E. and Nishimura, S. (1991) Mut. Res. 254, 1-12.

33. Tchou, J., Kasai, H., Shibutani, S., Chung, M.-H., Laval, J., Grollman, A. P. and Nishimura, S. (1991) Proc. Natl. Acad. Sci. USA 88, 4691-4694.

34. Chung, M.-H., Kim, H.-S., Ohtsuka, E., Kasai, H., Yamamoto, F. and Nishimura, S. (1991) Biochem. Biophys. Res. Comm. 178, 1472-1478.

35. Yamamoto, F., Kasai, H., Bessho, T., Chung, M.-H., Inoue, H., Ohtsuka, E., Hori, T. and Nishimura, S. (1992) Jpn. J. Cancer Res. 83, 351-357. 